\title{
Using of Polymers for Rapid Prototyping of an Axial Microturbine Runner and Wicked Gates
}

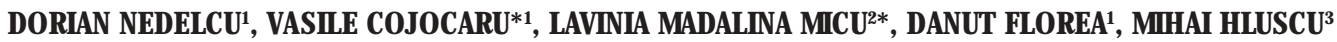 \\ ${ }^{1}$ Eftimie Murgu University of Resita, 1-4 Traian Vuia Sq., 320085, Resita, Romania \\ 2 University of Agricultural Sciences and Veterinary Medicine King Mihai I al Romaniei, 119 Calea Aradului, 300645, \\ Timisoara, Romania \\ ${ }^{3}$ Politehnica University, 2 Victoriei Sq., 300006, Timisoara, Romania
}

\begin{abstract}
Hydraulic turbine components that define the water flow, generally have a complex geometry. In the design of these components a major role is played by model tests. The complex geometry of runner's blades and wicked gates determines high manufacturing times and high fabrication cost if they are made by classical manufacturing technologies (casting, machining on numerically controlled machines). The use of high resolution 3D printing reduces the production time, simplifies the manufacturing technology and generate high dimensional accuracy. The paper presents the design and the manufacturing process of the components from a new solution of axial hydroturbine, equipped with a permanent magnet generator and an immersed runner. The manufacturing of the main parts of the turbine (runner and wicked gates) it was made by Rapid Prototyping.
\end{abstract}

Keywords: polymer, rapid prototyping, runner, wicked gates, axial microhydropower

Rapid Prototyping is a process that, through digital technologies, assures the design of a product, starting from the idea to its industrial achievement [1-4]. Thus, constructive and functional variants of a product can be analyzed and validated. Rapid Prototyping is a technology used to manufacture physical objects directly from files generated in a CAD program [5]. Several variants of 3D prototyping are available, all defined by the fact that geometry is created by depositing successive layers, thus adding material, contrary to classical methods, such as milling or turning, by which objects are generated by the removal of material.

Rapid Prototyping technology can be applied for various purposes, such as:

-rapid and low-cost exploration of constructive variants of the same piece;

-creating models that make it possible to highlight design errors before starting the mass production;

-building assemblies of parts that can be analyzed and tested;

-use as models for castings;

The main advantages of using the 3D printer to generate the parts are: high precision, low manufacturing time, scalability of the geometry of the piece, the ability to print extremely complex geometries.

Considering the complex geometry of components used in aerodynamics and hydrodynamics, the use of 3D printing in these areas is fully justified. The literature offers examples of research in this direction. Olasek and Wiklak present the manufacturing of four models of a standard NACA0018 aerofoil using different materials and methods [6]. Shun and Ahmed [7] describe the design process and the additive manufacturing of a wind tunnel model. Aghanajafi and Daneshmand [8] compares the precision of an airfoil model manufactured by rapid prototyping with the precision of a model manufactured by traditional methods. Chica et al. [9] describe the manufacture of a pico hydraulic propeller turbine by advance computer solidification simulation and lost wax casting. The $3 \mathrm{~d}$ printing of a Pelton runner is described by Nedelcu et al.
[10] and Udroiu et al. [11]. The rapid manufacturing is used also by Quail et al. [12] for the development of a pump impeller, Wu etal. [13] for a hollow turbine blade and Koirala et al. [14] for a Francis turbine runner.

Considering the mechanical characteristics of polymers used for rapid prototyping, inferior to the characteristics of metallic materials [15-21] the use of additive technologies should be seen as an alternative to traditional technologies, especially for the prototype test (or model tests on hydraulic turbines).

This paper presents the design and the manufacturing process of the components from a new solution of axial hydroturbine, equipped with a permanent magnet generator and an immersed runner [12]. The manufacturing of the parts with complex geometry (runner and wicked gates) was made by rapid prototyping, using the Objet 30 Desktop Multifunctional 3D printer [23, 24] included in the endowment of the Center for Numerical Simulation and Prototyping from the Eftimie Murgu University of Resita.

\section{The microturbine design}

The constructive solution of the microturbine

The constructive solution of the microturbine is presented in figure 1 and it is similar with a bulb turbine, with a conical wicked gate, an axial runner and a suction tube. The turbine can be entered through the upstream housing.

The stator has 2 blades and the wicked gate has 14 fixed blades on conical placement. The new concept of the microturbine is the use of the magnetic runner, which is placed on the axial runner periphery through 4 bolts, figure 2 . The magnetic runner consists of one disc with grooves and 24 neodymim magnets $(5 \mathrm{~mm} \times 10 \mathrm{~mm} \times 10$ $\mathrm{mm}$ dimensions), which are grouped into 2 pairs of poles. The neodymim magnets advantages are safe operation and excellent magnetic characteristics relative to smaller dimensions. Since the stator will come into contact with water, it will be sealed with resin. The two ends surfaces of the stator are closed with 2 caps and the inner is flooded

\footnotetext{
* email: v.cojocaru@uem.ro, Phone: 0741754875; lavimicu@yahoo.com
} 


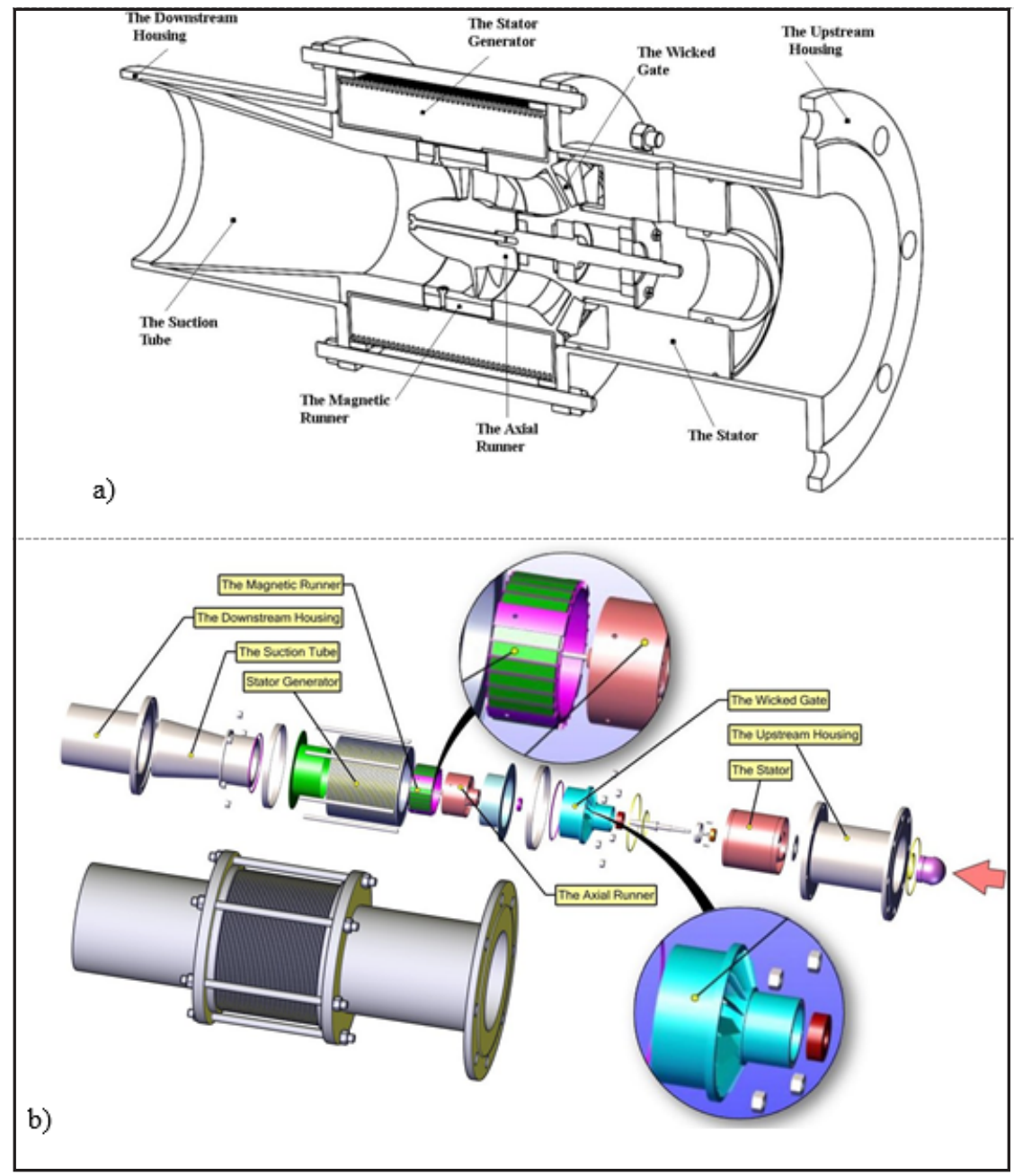

Fig. 1 The constructive solution of the microturbine ( $a$-section and $b$-exploded views)

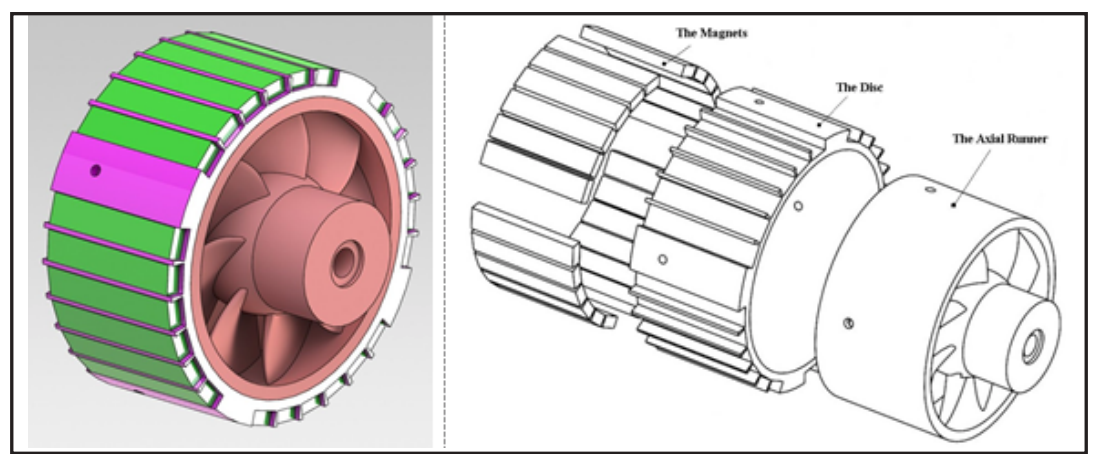

Fig. 2 The Axial Runner and the Magnetic Runner

Fig. 3 The microturbine geometry used in the simulation

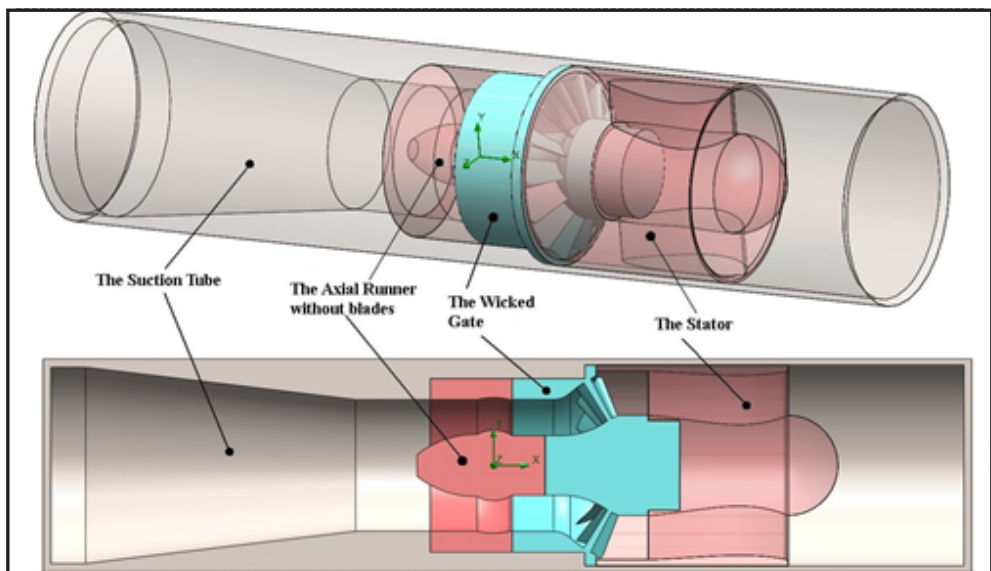

throughout with resin, which will provide sealing against water. The turbine can be removed through the suction tube and downstream housing.

The numerical simulation of flow through the microturbine The simulation of flow through the microturbine aimed to determine the variation of the meridian velocity in the

absence of the runner blades $[25,26]$. The simulation was performed using the Flow Simulation module, included in the SolidWorks software, for three operating points that will provide design data for the blade runners' hydrodynamic design: runner $\mathrm{R} 4 \rightarrow \mathrm{Q}=0.0109 \mathrm{~m}^{3} / \mathrm{s}$, runner $\mathrm{R} 6 \rightarrow \mathrm{Q}=$ $0.0106 \mathrm{~m}^{3} / \mathrm{s}$ and runner $\mathrm{R} 8 \rightarrow \mathrm{Q}=0.0094 \mathrm{~m}^{3} / \mathrm{s}$. Figure 3

( 


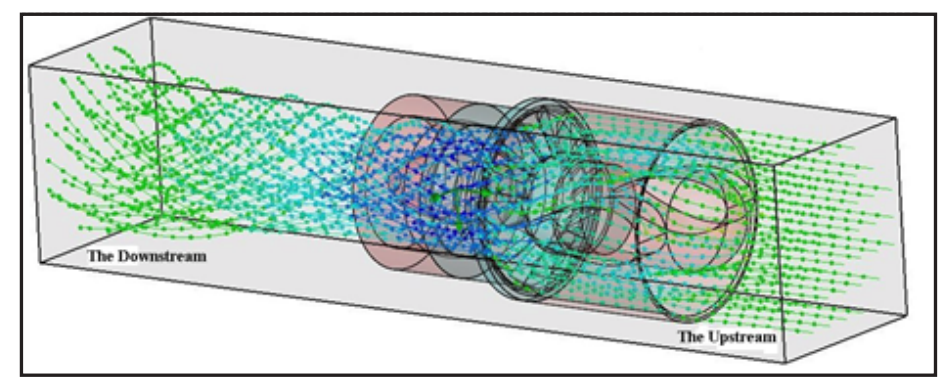

Fig. 4 The 3D streamlines through the microturbine

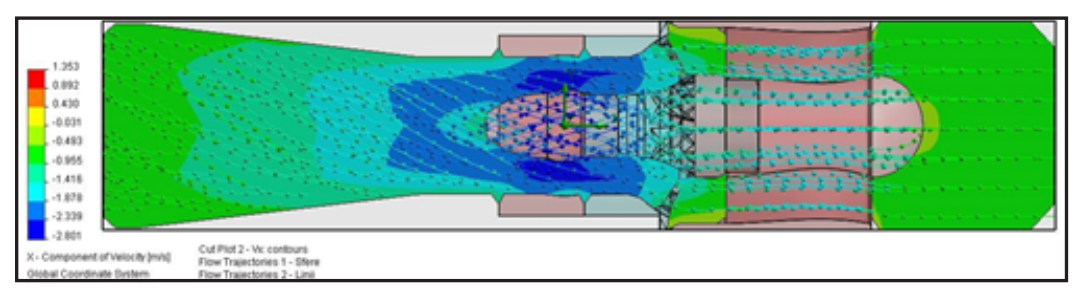

Fig. 5 The meridian velocity distribution for the R6 runner

shows the microturbine geometry that was used in the flow simulation. The imposed boundary conditions were: the discharge value $Q$ at the microturbine entrance surface and the atmospheric pressure at the exit surface.

Figure 4 shows the 3D streamlines through the microturbine. It is visible that the streamlines are horizontal and parallel with the axial direction of the flow. Also the streamlines are deviated by the wicked gate into a rotational movement. Figure 5 shows the meridian velocity distribution for the R6 runner.

Figure 6 shows the points from the runner area where meridian velocity values were taken from the flow simulation and Figure 8show the velocities distributions $V$, $V_{x^{\prime}} V_{y^{\prime}}, V_{z}$ as a function of radius for the R4, R6 and R8 rùnners, where $Y$ is the radial direction and $X$ is the flow direction.

The values of the meridian velocity $V_{x}$ are close to the values of the main velocity $V$, so the other's components of

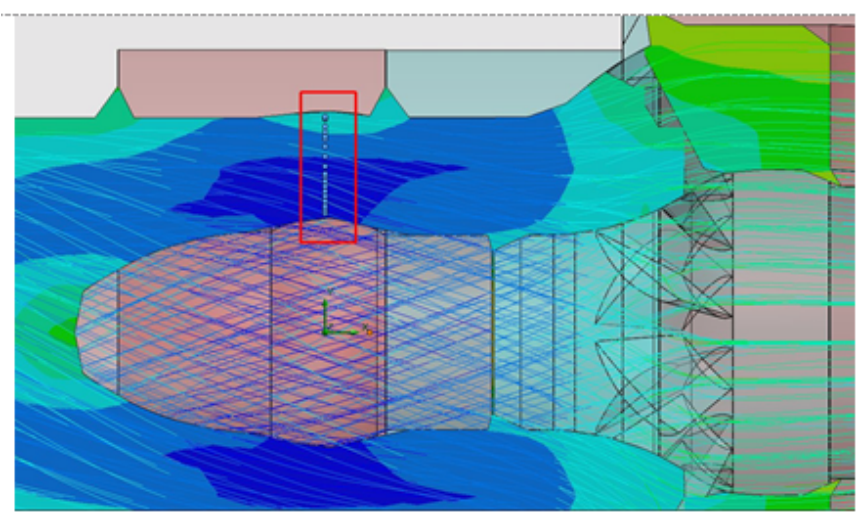

Fig. 6 The points where the meridian velocity values were taken from flow simulation the velocity $V_{y}$ and $V_{z}$ have smaller values. The meridian velocity values $V_{x}$ were used as input data for the $R 4, R 6$ and R8 blade runners' hydrodynamic design [22]. The difference between the three runners is generated by the number of blades.

\section{The Rapid Prototyping of the axial runners and the wicked gate}

The main steps performed for manufacturing the parts by rapid prototyping are:

-Generating the CAD file - done in an computer aided design software.

-Converting CAD file to Standard Triangulation Language (STL) - Stereolithography is a standardized format adopted in the Rapid Prototyping industry that stores the threedimensional surface of any object by means of a plane of triangles, the information pertaining to each triangle consisting of the coordinates of the three vertices and the direction of outer normal.

-The split of the object into layers - it is usually done in a specialized software supplied with the $3 d$ printing equipment; the object is split into a number of layers, the thickness of which varies depending on the equipment; the software also generates a support structure for the material during the $3 \mathrm{D}$ object printing; the model material is used to print the full parts of a pattern, and the support material is used to support the base material during the 3D object printing and to print the void volume in a pattern.

-Generation of the 3D part layer with layer - can be achieved by means of specific equipment, from various materials: polymers, composites, etc.

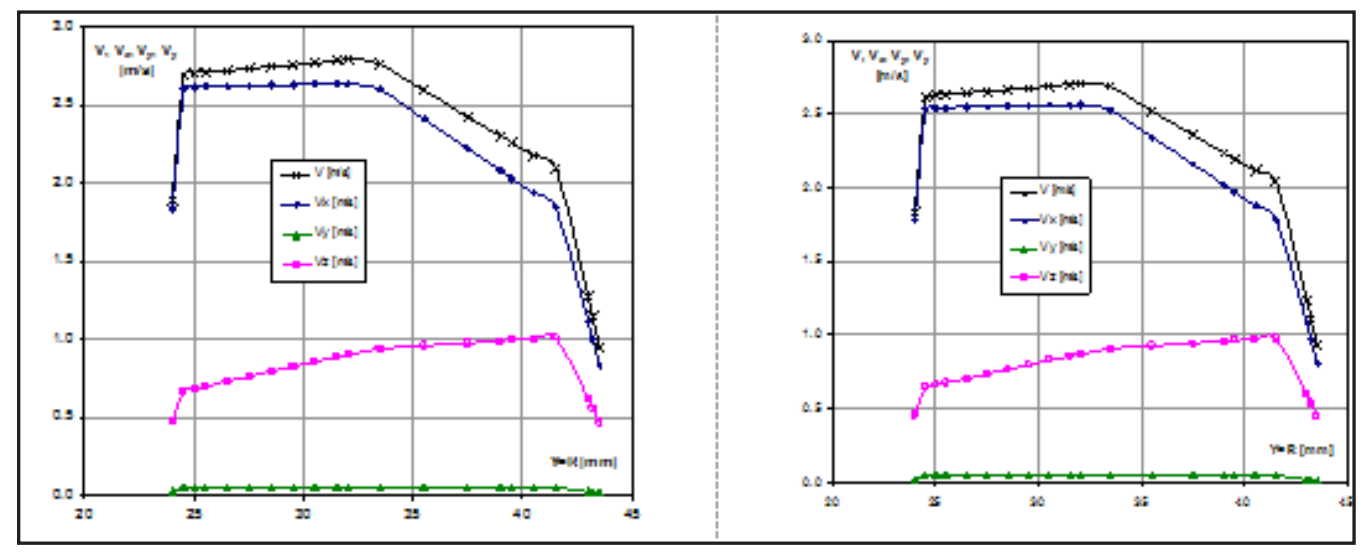

Fig. 7 The velocities distributions: a) R4 runner, b) R6 runner 


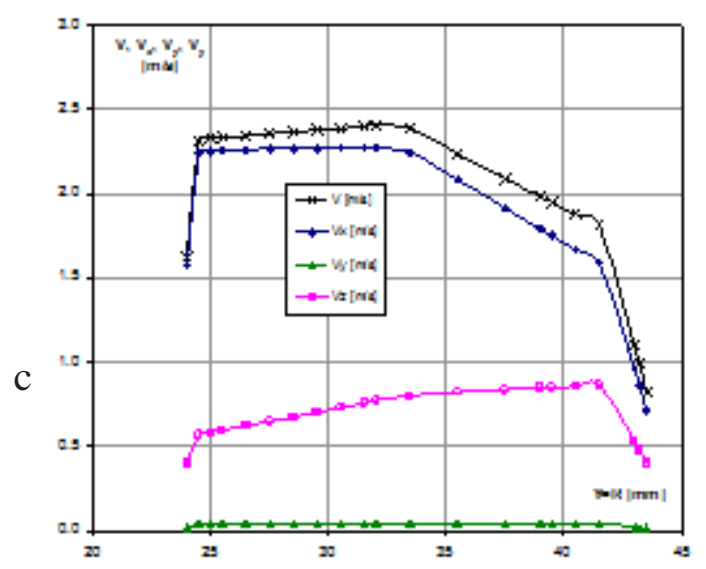

Fig. 7. The velocities distributions: c) R8 runner
Table 1

THE MATERIALS PROPERTIES

\begin{tabular}{|l|c|c|c|}
\hline \multicolumn{1}{|c|}{ Property } & UM & $\begin{array}{c}\text { DurusWhite } \\
\text { FullCure430 }\end{array}$ & $\begin{array}{c}\text { VeroBlack } \\
\text { FullCure 870 }\end{array}$ \\
\hline Tensile Strength & $\mathrm{MPa}$ & $20 \div 30$ & $50 \div 65$ \\
\hline Elongation at Break & $\%$ & $40 \div 50$ & $10 \div 25$ \\
\hline Modulus of Elasticity & $\mathrm{MPa}$ & $1000 \div 2000$ & $2000 \div 3000$ \\
\hline Flexural Strength & $\mathrm{MPa}$ & $30 \div 40$ & $75 \div 110$ \\
\hline Izod Notched Impact & $\mathrm{J} / \mathrm{m}$ & $40 \div 50$ & $20 \div 30$ \\
\hline Shore Hardness (D) & Scale D & $83 \div 86$ & $83 \div 86$ \\
\hline Rockwell Hardness & Scale M & $73 \div 76$ & $73 \div 76$ \\
\hline Density & $\mathrm{g} / \mathrm{cm}^{3}$ & $1.15 \div 1.17$ & $1.17 \div 1.18$ \\
\hline
\end{tabular}

Table 2

THE 3D PRINTING PARAMETERS

\begin{tabular}{|c|c|c|c|c|c|c|c|}
\hline The part & Material & $\begin{array}{c}\text { Number of } \\
\text { Layers }\end{array}$ & $\begin{array}{c}\text { Number } \\
\text { of Triangles }\end{array}$ & $\begin{array}{c}\text { Dimensions } \\
{[\mathrm{mm}]}\end{array}$ & $\begin{array}{c}\text { Model } \\
\text { Material }\end{array}$ & $\begin{array}{c}\text { Support } \\
\text { Material }\end{array}$ & $\begin{array}{c}\text { The Printing } \\
\text { Time }\end{array}$ \\
\hline The R8 Runner & $\begin{array}{c}\text { Vero } \\
\text { Black }\end{array}$ & 2696 & 299104 & $\Phi 96 \mathrm{x} 55$ & $413 \mathrm{~g}$ & $281 \mathrm{~g}$ & $17 \mathrm{~h} 00 \mathrm{~min}$ \\
\hline $\begin{array}{c}\text { The R4 \& R6 } \\
\text { Runners }\end{array}$ & $\begin{array}{c}\text { Durus } \\
\text { White }\end{array}$ & 3055 & 3938054 & $\Phi 96 \mathrm{x} 55$ & $762 \mathrm{~g}$ & $473 \mathrm{~g}$ & $19 \mathrm{~h} 15 \mathrm{~min}$ \\
\hline The Wicked Gate & $\begin{array}{c}\text { Vero } \\
\text { Black }\end{array}$ & 3991 & 227212 & $\Phi 132 \times 111$ & $786 \mathrm{~g}$ & $628 \mathrm{~g}$ & $29 \mathrm{~h} 08 \mathrm{~min}$ \\
\hline & & & & Total & $1691 \mathrm{~g}$ & $1382 \mathrm{~g}$ & $65 \mathrm{~h} 23 \mathrm{~min}$ \\
\hline
\end{tabular}

-Cleaning and finishing the object- consists in extracting the object from the equipment; for some polymeric materials it is necessary to remove the support material by various techniques, such as pressurized water jets. Finally, various operations can be applied: surface treatment by sandblasting or painting, which improves the visual appearance and the duration of use of the object.

For the axial hydroturbine equipped with permanent magnet generator and immersed runner, two components with complex geometry were executed through the rapid prototyping technology - the wicked gates and the runner (three variants of runners were manufactured: R4-4 blades, R6 -6 blades and R8 -8 blades).

The rapid prototyping equipment used was the Objet 30 Desktop multifunctional printer, from Center for Numerical Simulation and Prototyping of Eftimie Murgu University, which can be used for multiple applications based on various material. The technology used on this equipment consists in depositing on the printing tray of several successive layers of photopolymers, with thickness of
$28 \mu \mathrm{m}$, until the piece is finished. Each layer of photopolymer deposited on the tray is immediately hardened by an ultraviolet lamp. The support material can be easily manually removed by a pressurized water jet. Accuracy can vary with the geometry, orientation, and object size, within a range of $0.1-0.2 \mathrm{~mm}$.

The model material (base material) used to print the R8 runner and the wicked gates was Objet VeroBlack FullCure 870 , and for the R4 and R6 runners the DurusW hite FullCure430 material was used. The main properties of the two materials, as indicated by the manufacturer, are synthesized in table 1.

The $3 \mathrm{~d}$ geometry of the parts was designed in Solid Works. From SolidWorks, the 3D geometry was exported in STL format and imported into the Objet Studio software, an application that manages the entire process of the 3D printing. Table 2 shows the printing parameters.

Figure 8 show the STL geometry, the placement of on the print tray (in the Objet Studio software) and the final geometry of the R8 runner. Figure 9 the placement of on
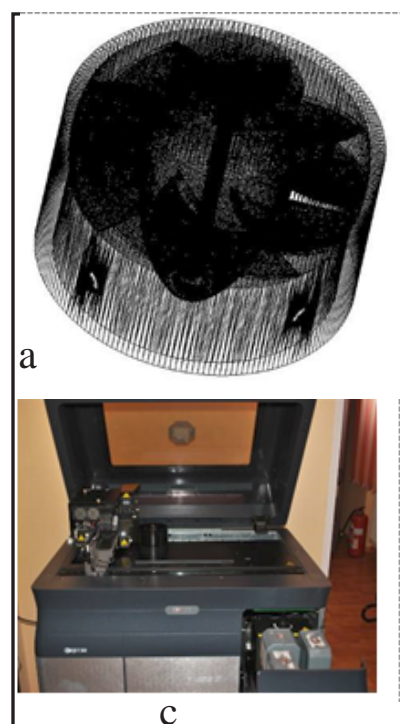

b

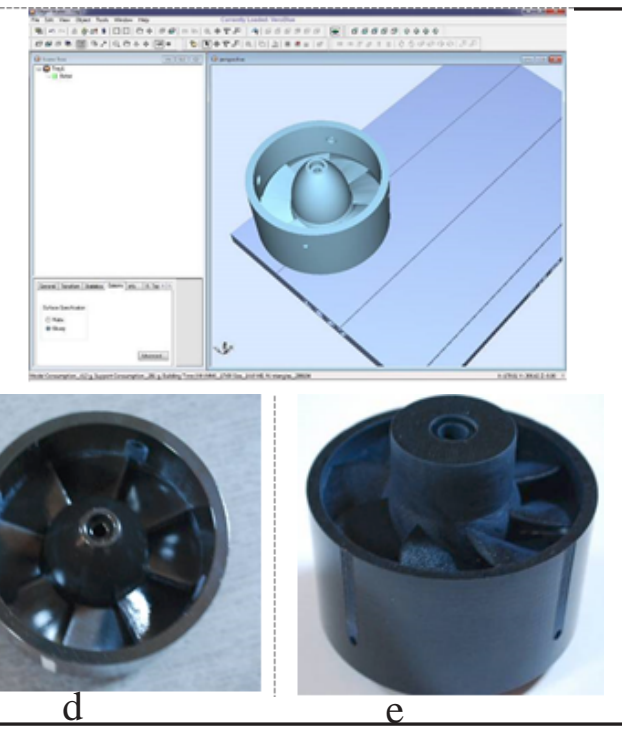

Fig. 8 Rapid prototyping of R8 runner: a) STL model of the R8 runner, b) placement of the R8 runner on the print tray, c), d), e) final geometry of the R8 runner 

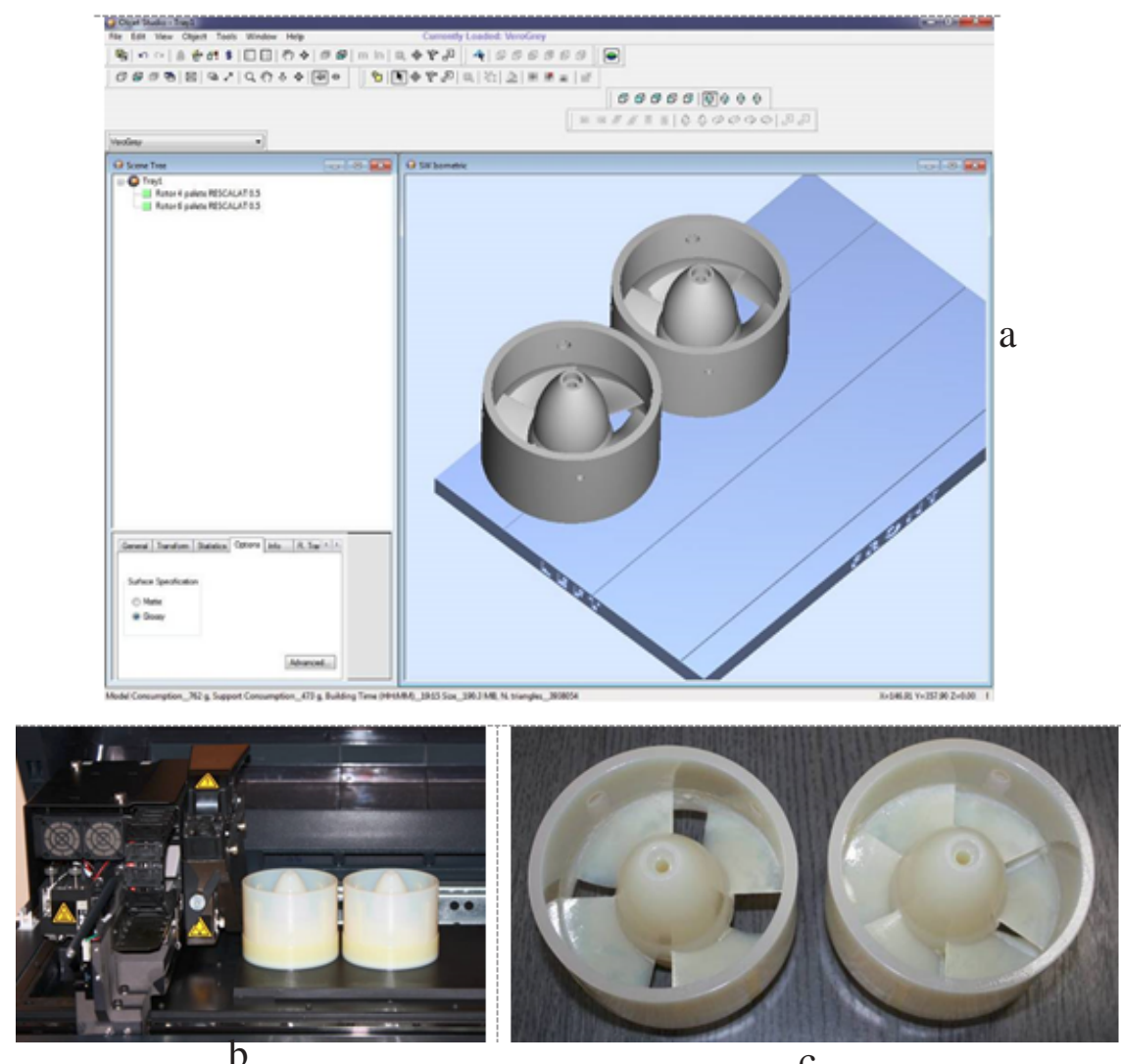

C

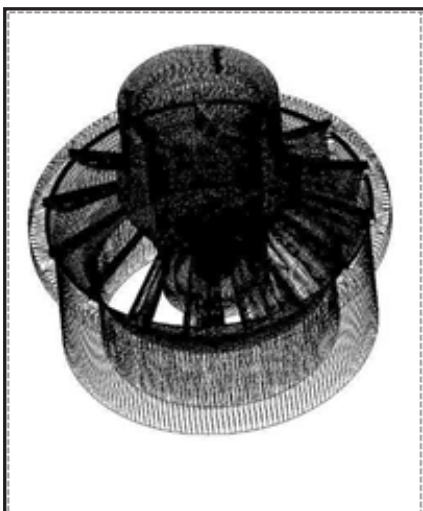

a)

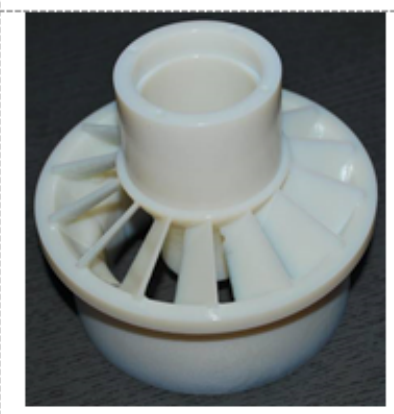

c)

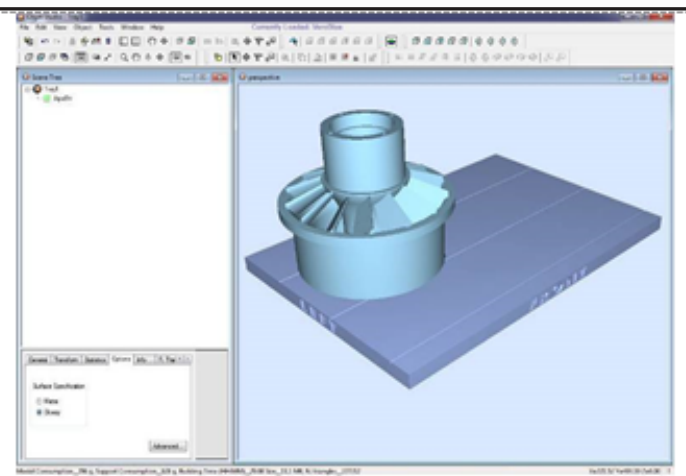

b)

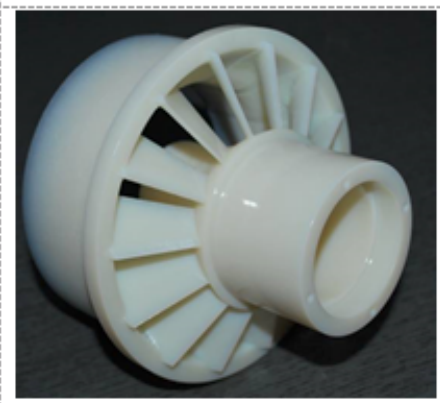

d)

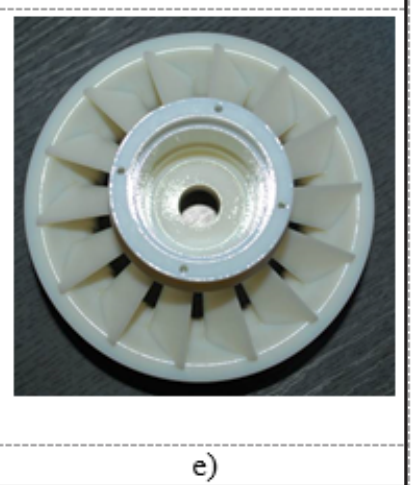

e)

Fig. 9 Rapid prototyping of R4 and R6 runners: a) placement of the $R 4$ and $R 6$ runners on the print tray, b) and c) final geometry of the R4 and R6 runners

Fig. 10 Rapid prototyping of the Wicked Gate a) STL geometry, b) the placement of the Wicked Gate on the print tray, c), d) and e) final geometry of the Wicked Gate

the print tray and the final geometry of the R4 and R6 runners. The R4 and R6 runners were printed togheter. Figure 10 shows the STL geometry, the placement on the print tray and the final geometry of the wicked gates.

The total time required for the manufacture of the three runners and the wicked gates was $65 \mathrm{~h}$ and 23 min and the total material consumption was 1961 grams of model material and $1382 \mathrm{~g}$ of support material.

\section{Conclusions}

The paper presents a concept of axial microturbines equipped with a magnetic generator, where the magnetic runner is fixed on the axial runner periphery. The final constructive solution of the microturbine and of the three types of axial runners with different blade numbers was presented. The hydrodynamic parts with complex geometry (the axial runners and the wicked gate) were manufactured by Rapid Prototyping technology. The 
numerical results obtained on the experimental stand for all the designed runners geometry $(R 4, R 6, R 8)$ falls in the $66.2 \div 108.0 \mathrm{~W}$ power range and between $28 \div 51.98 \%$ efficiency values. The efficiency values are small compared to current microturbines, because the prototype was not provided with the blade adjustment of the wicked gate. The aim of this solution was only to verify the functionality of the new design consisting of coupling the magnetic with the axial runner and rotating them inside the stator of the generator with direct water contact. The solution has obvious advantages: removing the gear tooth transmission between the axial and the generator runner, a compact configuration, reduced weight, simple maintenance and a low cost. The modern Rapid Prototyping technology was the manufacturing method selected to create the complex geometry of the runners and wicked gate at a significantly lower price and execution time than the conventional manufacturing technologies. Experimental research on the stand in the water environmenthas highlighted the practical utility of polymers as a possible material to test prototype equipment, allowing components to work at high speed over the entire period of the tests.

\section{References}

1.FERREIRA J.C., SANTOS E., MADUREIRA H., CASTRO J ., Integration of VP/RP/RT/RE/RM for rapid product and process development, Rapid Prototyping J ournal, 12, 2006, p. 18-25

2.GUO N, LEU C.G., Additive manufacturing: technology, applications and research needs, Frontiers of Mechanical Engineering, 8, no. 3, 2013, p. 215-243

3.CARUTASU, N. L., SIMION, I., CARUTASU, G., JIGA, G., AUREL ARION, A.F., Experimental Test for Elastic and Mechanical Evaluation of ABS Plastic Used in 3D Printing, Mat. Plast. 52, no.3, 2015, p. 398

4.VASILESCU, M. D., FLESER, T., Influence Of Technological Parameters on the Dimension of Gear Parts Generated with PLA Matherial by FDM 3d Printing, Mat. Plast., 55, no. 2, 2018, p. 247

5.TUT, V., TULCAN,A., COSMA, C., SERBAN, I., Application of CAD/ CAM/FEA, reverse engineering and rapid prototyping in manufacturing industry. International Journal of Mechanics, Vol.4, Issue 4, 2010, p.79-86

6.OLASEK K., WIKLAK P., Application of 3D printing technology in aerodynamic study, XXI Fluid Mechanics Conference, Journal of Physics, Conference Series, 530, 012009, 2014

7.SHUN S., AHMED N.A., Rapid prototyping of aerodynamics research models, Applied Mechanics and Materials, 217, 2012, p. 2016-2025

8.AGHANAJ AFI C. DANESHMAND S., Integration of Three-Dimensional Printing Technology for Wind-Tunnel Model Fabrication, Journal of Aircraft, 47, No. 6, 2010, p. 2130-2135

9.CHICA E., AGUDELO S., SIERRA N., Lost wax casting process of the runner of a propeller turbine for small hydroelectric power plants, Renewable Energy, 60, 2013, p. 739-745

10.NEDELCU, D., COJOCARU V., GHICAN A., PERIS-BENDU F., AVASILOAIE R., Considerations regarding the use of polymers for the rapid prototyping of the hydraulic turbine runners designed for experimental research on the model, Mat. Plast., 52, no. 4, 2010, p. 475-479
11.UDROIU R., NEDELCU A., DEAKY B., Rapid manufacturing by polyjet technology of customized turbines for renewable energy generation, Environmental engineering and management journal, 10 (9), 2011, p. $1387-1394$

12.QUAIL F., STICKLAND M., SCANLON T., Rapid Manufacturing Technique used in the Development of a Regenerative Pump Impeller, Proc. World Congress on Engineering, WCE '09, vol. 2, London, U.K, 2009, p. 1730-1736

13.WU H., LI D., GUO N., Fabrication of integral ceramic mold for investment casting of hollow turbine blade based on stereolithography, Rapid Prototyping J ournal, 15, 2009, p. 232-237

14.KOIRALA R., CHITRAKAR S., PANTHEE A., NEOPANE H.P., THAPA B., Implementation of Computer Aided Engineering for Francis Turbine Development in Nepal, International Journal of Manufacturing Engineering, 1, 2015, p. 1-9

15.TABACU, S., HADAR, A., MARINESCU, D., MARIN, D., DINU, G., IONESCU, S.D., Structural performances of thermoplastic manufactured parts, Mat. Plast., 45, no. 1, 2008, p. 113-118

16.MARSAVINA, L., CERNESCU, A., LINUL, E., SCURTU, D., CHIRITA, C., Experimental Determination and Comparison of Some Mechanical Properties of Commercial Polymers, Mat. Plast., 47, no. 1, 2010, p. 8589

17.HAGUE R., MANSOUR S., SALEH N., HARRIS R., Materials analysis of stereolithography resins for use in Rapid Manufacturing, Journal Of Materials Science, 39, 2004, p. 2457 - 2464

18.CAPLESCU, C., MARSAVINA, L., BORDEASU, I., SECHEI, R.M., The Fracture of Polyurethane Materials in the Presence of Stress Concentrators, Mat. Plast., 47, no. 3, 2010, p. 379-382

19.MICU, L. M., LAZAR, I., CIRCIUMARU, A., BORDEASU, I., PIRVULESCU, L.D., HLUSCU, M., New Results Regarding Cavitation Behavior of Polymers Modified with Anorganic Substances Coated on Bronze Surfaces, Mat. Plast., 55 , no. 3, 2018, p. 460-463

20.ANTON, L.E., BORDEASU, I., TABARA, I., Considerations regarding the use of EPO $99 \mathrm{~B}$ resin in manufacturing AXIAL hydraulic machinery runners, Mat. Plast., 45, no. 2, 2009, p. 190-192

21.BORDEASU, I., CIRCIUMARU, A., POPOVICIU, M., LAZAR, I.,BADARAU, R., GROZA, I., Cavitation Erosion Behavior on Thin Films of Polymer Blends Deposited Over Bronze Surfaces, Mat. Plast., 55 , no. 3, 2018, p. 286-290

22.FLOREA D., Theoretical and experimental research on an axialtubular microturbine equipped with permanent magnet generator and immersed runner, PhD thesis, PhD Leader Dorian Nedelcu, Eftimie Murgu University of Resita, 2013

23.*** Objet30 ${ }^{\mathrm{TM}}$ 3-D Printer System, User Guide, Objet Geometries Ltd., 2010

24.*** Polyl et ${ }^{\mathrm{TM}}$ Materials Data Sheet, 2014

25.ANTON, A. A., CRETU, V., RUPRECHT, A., MUNTEAN, S., TRAFFICREPLAY COMPRESSION (TRC): A HIGHLY EFFICIENT METHOD FORHANDLING PARALLEL NUMERICAL SIMULATION DATA, Proceedingsof ihe Romanian Academy Series A-Mathematics Physics TechnicalSciences Information Science, Volume 14, Issue 4, 2013, pp. 385-392

26.ANTON, A. A., MUNTEAN, S., SUSAN-RESIGA, R. F., SWIRL2D: ANINTERFACE TRACKING ALGORITHM FOR COMPUTING THE TWODIMENSIONAL SWIRLING FLOWS WITH STAGNANT REGION, Proceedings of ihe Romanian Academy Series A-Mathematics PhysicsTechnical Sciences Information Science, Volume 17, Issue 4, 2016,pp. 366-373

$\overline{\text { Manuscript received: } 17.03 .2019}$ 